\title{
SUICIDAL BEHAVIOR IN PALLIATIVE CARE PATIENTS
}

Nuno Agostinho Fernandes ${ }^{1}$; Marisa Martins ${ }^{1}$, Liliana Ferreira ${ }^{1}$, Ricardo Gasparinho ${ }^{1}$, Núria Santos ${ }^{1}$, António Alho ${ }^{1}$, Inês Fernandes ${ }^{1}$, Ana Ricardo², Ana Mendes ${ }^{1,2}$, Marta Oliveira ${ }^{2}$

${ }^{1}$ Hospital Distrital de Santarém (HDS), EPE - Psychiatry and Mental Health Department (Portugal)

${ }^{2}$ Hospital Distrital de Santarém (HDS), EPE - In-Hospital Palliative Care Team (Portugal)

Background: Severe physical illness is a risk factor for suicide in the general population. It is believed that palliative care patients (PCP) with advanced stage cancer are more likely to commit suicide due to the presence of multiple risk factors such as pain, depression, hopelessness, poor prognosis, exhaustion, fatigue, preexisting psychopathology, personal history of suicide attempt and family history of suicide.
Objectives: Describe 2 clinical cases of PCP with suicidal behavior (SB). Conduct a review on SB in PCP.

Materials and methods: Description of clinical cases and research in PubMed with the words "suicide" and "palliative care".

\section{Results}

Case 1: Male, 73 years, married.

With lung cancer and bone metastasis followed by the palliative care team (PCT).

No psychiatric history.

Family psychiatric history of suicide by hanging.

He was admitted to the psychiatric ward for structured suicidal ideation. He presented depressed mood, fatigue, insomnia, loss of appetite, suicidal ideation by hanging, and uncontrolled pain.
Case 2: Male, 59 years, married.

With lung cancer and bone metastasis followed by PCT. History of abusive alcohol consumption, with no other psychiatric history.

With no family psychiatric history.

He made 2 suicide attempts in the 3 days prior to hospitalization. He was admitted to the psychiatric ward for suicide risk. He presented depressed humor, confusion, persecutory delusions, isolation, insomnia, loss of appetite, unstructured suicidal ideation, and uncontrolled pain.

There are few studies published in the last 10 years on suicide in palliative care. They identified multiple risk factors, such as physical pain and suffering, depression and feeling hopeless, disinhibition, confusion and delirium, helplessness and the loss of control, advanced illness and poor prognosis, exhaustion and fatigue, pre-existing psychopathology, a history of prior suicide attempts and family history.

Filiberti et al. conclude that concerns regarding autonomy, not only considered as poor performance status but above all as fear of losing independence and of being a burden on others can be considered the most relevant vulnerability factor for palliative care patients committing suicide. Moreover, associated factors, such as uncontrolled pain, depression with a feeling of hopelessness, fear of suffering, serious body impairments, negative emotional reaction to treatments received, and the adverse physical consequences left by these are important contributing risk factors.

The described patients presented several risk factors for suicide, namely uncontrolled pain, depression, isolation, fatigue, confusion, and a family history of suicide.

\section{Conclusions}

The loss of autonomy and the perception of overload for the relatives seem to be more relevant as factors of vulnerability for the SB in PCP.

It is important to recognize risk factors in order to prevent SB in these patients.

1. Filiberti A, Ripamonti C, Totis A, Ventafridda V, De Conno F, Contiero P et al. Characteristics of Terminal Cancer Patients Who Committed Suicide During a Home Palliative Care Program. Journal of

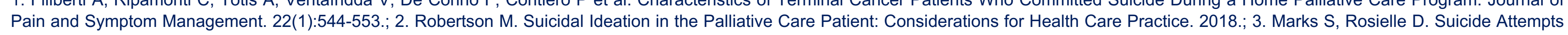
in the Terminally III. Journal of Palliative Medicine. 2012;15(9):1037-1038.; 4. Choy C. Suicide in palliative care setting. Annals of Palliative Medicine. 2017;6(S2):S264-S265. 